\title{
A New Cinch Back Instrument with Tucker for Orthodontic
} Purpose

\author{
Dr. Rahul Motwani ${ }^{1}$, Dr. Vikas Gill ${ }^{2}$, Dr Lovleen Kaur ${ }^{3}$, Dr. Chiranjeev saini ${ }^{4}$, \\ Dr. M. Hussain ${ }^{5}$ \\ ${ }^{1}$ (Department Of Orthodontics And Dentofacial Orthopedics, Rajasthan Dental College And Hospital, Jaipur, \\ Rajasthan, India). \\ ${ }^{2}$ (Reader, Department Of Orthodontics And Dentofacial Orthopedics, Rajasthan Dental College And Hospital, \\ Jaipur, Rajasthan, India). \\ ${ }^{3}$ (Department Of Oral Medicine And Radiology, Rajasthan Dental College And Hospital, Jaipur, Rajasthan, \\ India). \\ ${ }^{4}$ (Department Of Orthodontics And Dentofacial Orthopedics, Rajasthan Dental College And Hospital, Jaipur, \\ Rajasthan, India). \\ ${ }^{5}$ (Department Of Orthodontics And Dentofacial Orthopedics, Rajasthan Dental College And Hospital, Jaipur, \\ Rajasthan, India).
}

\begin{abstract}
Cinching instrument and tucker has been used by orthodontist since many years which are very costly and bulky in use. This is a clinical innovation which results in a cinch back instrument with tucker. Instead of using costly and bulky instruments, we innovated a new instrument which can be easily made in negligible cost and time. We have taken a discarded probe and soldered it with discarded tube and we got distal end cinching instrument. We have added and modified with tucker also by making the round surface of probe plain and placing a ditch over it. Here we get cinching instrument with tucker in negligible time and cost. We can use it as tucker and as cinching instrument both with same result which came with two different instruments.
\end{abstract}

Keywords: cinching instrument, discarded probe, discarded tube, tucker.

\section{Introduction}

The concept of making a new cinch back instrument with tucker is to make the cinching procedure easy $\&$ cost effective instrument. New cinch back plier with tucker is fabricated by discarded probe \& 035 needle. Needle is trimmed and soldered to the probe in two different angle( straight\& angled ). The end part of the probe which is round and useless made flat by trimmer and a ditch is made with straight probe.

\section{Fabrication}

New cinch back instrument with tucker is fabricated by using:-

1. A discarded probe

2. 035 needle straight part

3. Solder and flux

\section{STEPS IN CONSTRUCTION}

1. We can take two discarded probe's with straight and angled beak.

2. Straight part of 035 needle has been taken.

3. Needle has been soldered with straight and angled probe with the help of hydrosolder machine as shown in fig 1.

4. After soldering the tube we can make the round surface of probe plain and placing a ditch over it as shown in fig 2.

\section{USES}

- Single instrument for cinch back \& tucker as shown in figure $3,4 \& 5$

- In lingual case also by straight and angled instrument.

- Multiple purpose

\section{Advantages}

- Accuracy in holding the wire and in cinching

- Decreased chair side time 
- $\quad$ Effectively used

- Negligible cost

- $\quad$ Easy to fabricate.

- $\quad$ Safe to use

\section{Figures}

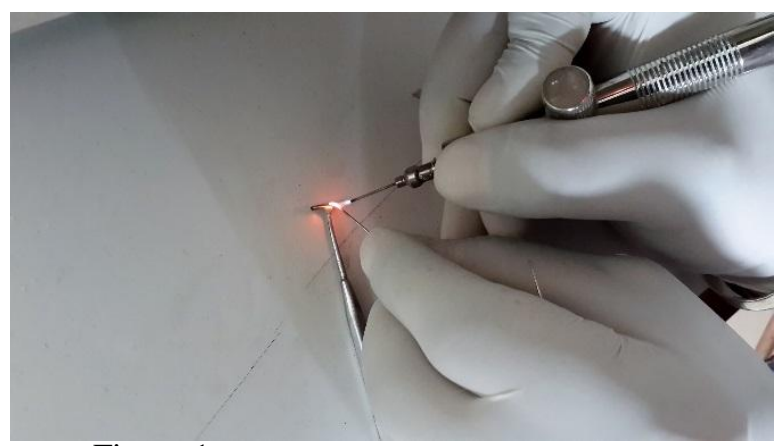

Figure 1

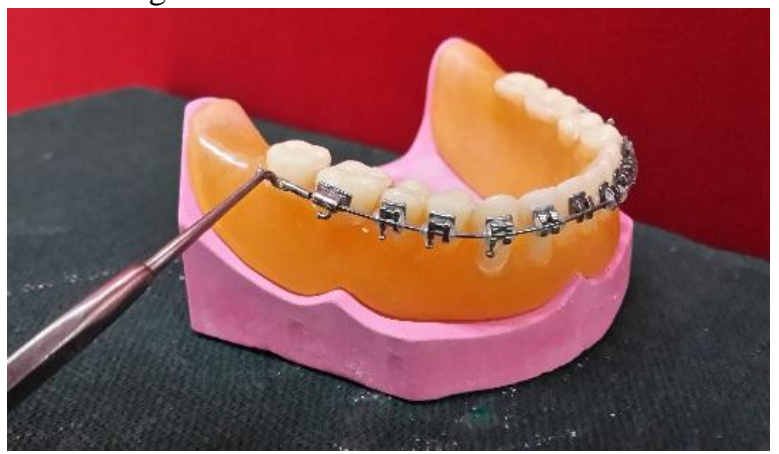

Figure 4
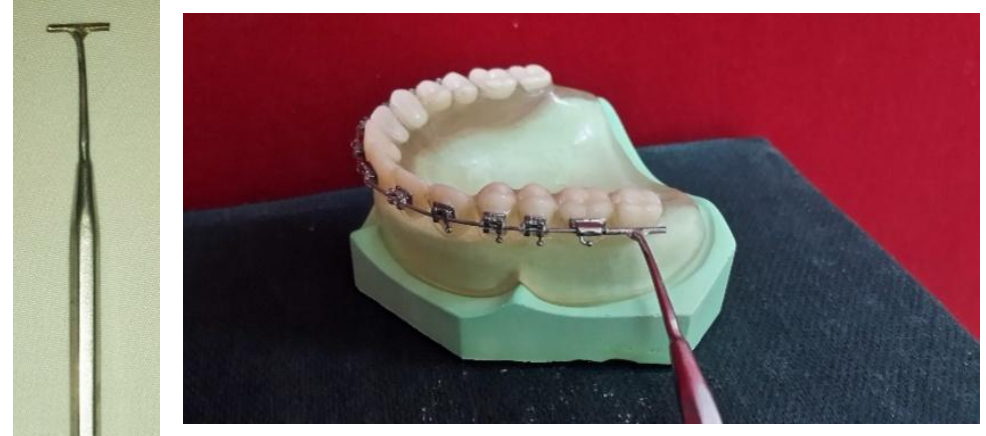

Figure 3

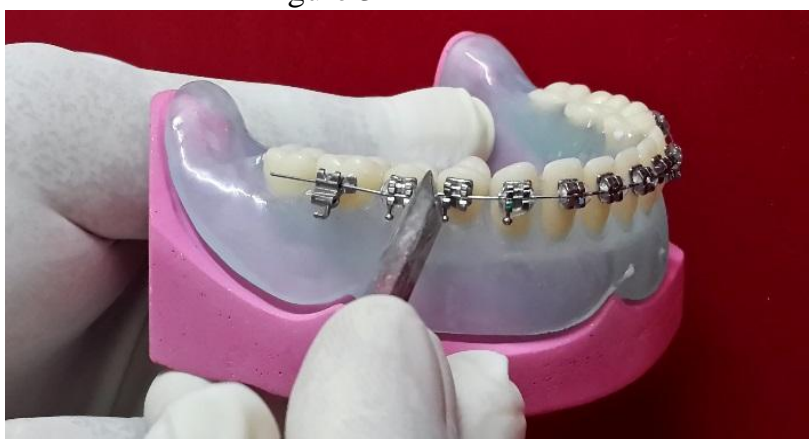

Figure 5

\section{Conclusion}

This multipurpose new cinch back instrument with tucker has emerged as single tool for clinical purpose. It has incorporated with tucker henceforth reducing manual efforts \&chair side time. It can be used for both cinching and tucking the wire. Also the device has cost effectiveness with no fabrication cost, and can be made easily by own. It can be seen as futuristic approach to orthodontics and can be used in clinical practice with great ease. 